\title{
"As pessoas sentem muito poder em dizer não": moralidades e direitos nas audiências para concessão de certidão de nascimento
}

"People feel a lot of power in saying no": moralities and rights in the birth certificate hearings

\section{Fernanda Melo da Escóssia}

Brasil. Instituto Brasileiro de Mercado de Capitais. Jornalista, professora e pesquisadora. Doutora em História, Política e Bens Culturais no Centro de Pesquisa e Documentação de História Contemporânea do Brasil (CPDOC)/Fundação Getulio Vargas (FGV). Mestra em Comunicação pela Universidade Federal do Rio de Janeiro (UFRJ). ID ORCID: http://orcid.org/0000-0001-7793-4555. E-mail:fernanda.daescossia@uol.com.br.

\section{Resumo}

O artigo examina audiências judiciais realizadas em um serviço público e gratuito de emissão de certidão de nascimentos num ônibus mantido pelo Tribunal de Justiça do Estado do Rio de Janeiro. Brasileiros adultos sem documento tentam provar à Justiça que são quem dizem ser e, nesse processo, acionam memórias para reconstruir trajetórias. A autora dialoga com o entendimento de Geertz de que o Direito é um saber local e analisa como a decisão judicial resulta de uma operação em que são mobilizadas muitas instâncias - memória, conhecimento jurídico e interpretação -, numa intersecção permanente entre saberes formais e vivências, legalidades e moralidades. $\mathrm{O}$ artigo é resultado de dois anos de trabalho etnográfico da autora e inclui parte da pesquisa realizada para sua tese de doutorado, defendida em abril de 2019 no Centro de Pesquisa e Documentação de História Contemporânea do Brasil (CPDOC)/Fundação Getulio Vargas (FGV).

Palavras-chave: Etnografia, Registro de Nascimento, Direitos, Moralidades. 


\section{Abstract}

This article examines judicial hearings in a free public service for issuing birth certificates in a bus maintained by the Court of Justice of the State of Rio de Janeiro. Brazilian adults without such documents try to prove in court that they are who they say they are. In this process, they trigger memories to reconstruct trajectories. The author dialogues with Geertz's understanding that law is local knowledge and analyzes how the judicial decision results from an operation in which many instances are mobilized - memory, legal knowledge, and interpretation, in a permanent intersection between formal knowledge and experiences, legalities and moralities. This is the result of two years of ethnographic work by the author and includes part of the research for her doctoral thesis, approved in April of 2019 in the CPDOC/FGV.

Keywords: Ethnography, Birth Registration, Rights, Moralities.

\section{INTRODUÇÃO E NOTA METODOLÓGICA}

Da porta do ônibus, uma funcionária chama alto o nome completo de Raimundo. É o início de uma sexta-feira nublada, 26 de maio de 2017, e mais de quarenta pessoas esperam espalhadas pelo pátio do Juizado da Infância e da Adolescência, na Praça Onze, bairro do centro do Rio. Raimundo tem na cabeça um cocar indígena de penas azuis, vermelhas, verdes, amarelas e pretas. Veste bermuda e camiseta. O rosto está pintado de preto e vermelho e, no pescoço, ele traz um colar de peças brancas. Raimundo entra no ônibus acompanhado por uma mulher de cocar. Adultos, velhos e crianças olham. Todos aguardam a hora de entrar no ônibus azul e branco, onde funciona um serviço público e gratuito que emite o documento que eles nunca tiveram: a certidão de nascimento.

O ônibus da Praça Onze trabalha exclusivamente emitindo certidões de nascimento, numa parceria entre dois projetos do Tribunal de Justiça do Estado do Rio de Janeiro: a Justiça Itinerante e o Serviço de Promoção e Erradicação do Sub-registro de Nascimento e a Busca de Certidões (Sepec). Por dois anos 
acompanhei o atendimento no ônibus, em pesquisa de cunho etnográfico realizada para a tese de doutorado defendida em abril de 2019 no Centro de Pesquisa e Documentação de História Contemporânea do Brasil (CPDOC)/ Fundação Getulio Vargas (FGV) que dá origem a este artigo. Na pesquisa, investiguei como brasileiros adultos sem qualquer documento conseguem no ônibus a certidão de nascimento. Dados do Instituto Brasileiro de Geografia e Estatística - IBGE (2016) mostram que, principalmente com a ampliação dos programas de transferência de renda, caiu muito a taxa de subrregistro, o número de crianças não registradas no mesmo ano ${ }^{1}$. Não há dados exatos sobre adultos, foco de minha pesquisa.

Inspirada pela indagação de Peirano (2006) - de que serve um documento? -, a pesquisa analisa de que modo o processo de obtenção da certidão de nascimento traz à tona concepções de direitos e cidadania expressas por brasileiros adultos que procuram o serviço no centro do Rio de Janeiro. Reflete sobre o documento como elemento constitutivo da identidade, como já trataram Santos (1979), DaMatta (2002) e Peirano (2006), e sobre a documentação como direito garantido pela legislação nacional e internacional ${ }^{2}$. Este artigo apresenta um momento específico da pesquisa: as audiências no ônibus, quando pessoas adultas sem documento são recebidas pelos juízes e juízas. Como uma pessoa sem documentos prova à Justiça que é quem diz ser? Como isso será julgado diante do juiz?

Em busca de respostas, a pesquisa dialoga com a antropologia do Estado e a antropologia do direito, a fim de compreender como o Estado e seus limites

\footnotetext{
O subrregistro é definido pelo IBGE como o conjunto de nascimentos não registrados no ano de ocorrência ou até o fim do primeiro trimestre do ano seguinte. A estimativa é calculada pela diferença entre os nascimentos estimados e os informados pelos cartórios. Segundo o IBGE, a taxa de subrregistro caiu de 20,3\% em 2002 para 3,2\% em 2015 (INSTITUTO BRASILEIRO DE GEOGRAFIA E ESTATÍSTICA, 2016).

2 O Pacto Internacional sobre Direitos Civis e Políticos, adotado pela XXI Sessão da Assembleia-Geral das Nações Unidas, em 16 de dezembro de 1966, estabelece em seu artigo 24, parágrafo 20: "Toda criança deverá ser registrada imediatamente após seu nascimento e deverá receber um nome”. Em 1969, a Convenção Americana sobre Direitos Humanos, conhecida como Pacto de São José da Costa Rica, tratou do direito ao registro, explicitando o direito ao prenome e aos nomes dos pais no documento, mediante nomes fictícios, se necessário. No Brasil, só com o fim da ditadura militar e após a promulgação da Constituição de 1988 o Brasil aprovou o Pacto sobre Direitos Civis e Políticos, por meio do Decreto Legislativo nº 226, de 12 de dezembro de 1991. Em 1992, aderiu ao Pacto de San José. A Constituição Federal Brasileira e o Código Civil também tratam do nome como direito e do registro civil como expressão desse direito.
} 
são construídos. A abordagem antropológica nos leva a estudar o Estado e suas margens em duas dimensões (SHARMA, GUPTA, 2006): as práticas cotidianas (as rotinas, os procedimentos burocráticos que muitas vezes parecem banais); e as representações desse Estado, ou seja, as formas que ele assume e por meio das quais se apresenta. Diante da Justiça Itinerante, uma instância do Estado-sistema (ABRAMS, 2006), será construída a prova de que as pessoas sem documentos são quem de fato dizem ser. A antropologia do direito, em diálogo com Vianna (2013), Eilbaum (2012), Ferreira (2015) e Lima (2012), nos faz privilegiar não a abordagem legal, filosófica ou jurídica do Direito, mas a compreensão dos direitos, no plural, como experiências e vivências, diz Vianna (2013), como busca e cidadania, da forma como proponho.

Etnografar o adulto sem documento é mergulhar no que Das e Poole (2004) categorizam como "margens do Estado": práticas, lugares e linguagens existentes em espaços nos limites do funcionamento regulamentado do Estadonação, entendido o Estado como a presença que formata o sentido e as formas do poder em qualquer sociedade. O desafio trazido por Das e Poole - e que incorporo nesta pesquisa - é problematizar o conceito de margens e refletir sobre que relações se desenrolam nessas margens, tradicionalmente percebidas como áreas nas quais o Estado parece não estar presente - mas está, ainda que de modo não regular nem regulamentado. Margens do Estado também constituem o que chamamos Estado, pois este também se faz nas margens (DAS; POOLE, 2004). E tais margens, muitas vezes entendidas como áreas nas quais o Estado foi inábil para impor ordem, reorganizam suas práticas e experiências numa construção que não é monolítica, mas processual e dinâmica. Nas margens, a observação etnográfica de práticas e vivências mostra que exclusão e desordem convivem com resistência e pluralidade.

A opção metodológica pela etnografia foi decisiva para buscar interpretações sobre o significado de ter e não ter documentos. Geertz (1997) nos ajuda a compreender o saber jurídico e a construção dos fatos jurídicos como um saber local, um conhecimento alicerçado na observação de especificidades, práticas, casos, relatos, histórias e soluções, para, a partir daí, identificar princípios. A etnografia, como o direito, afirma Geertz, produz conhecimento 
dessa forma, entregando-se "à tarefa artesanal de descobrir princípios gerais em fatos paroquiais" (GEERTZ, 1997, p. 249).

Diferentemente de outras unidades da Justiça Itinerante ${ }^{3}$, o ônibus da Praça Onze, cujo trabalho começou em 2014, atende apenas pessoas que buscam a certidão de nascimento. Funciona às sextas-feiras e a média é de cinquenta atendimentos semanais. A cada sexta, Lúcia, comissária de Justiça, anota, por ordem de chegada, os nomes das pessoas que buscam atendimento e o que as leva até ali. Faz a triagem de casos. Como o ônibus só faz o registro de nascimento, quem quer outro documento, como Carteira de Trabalho e Previdência Social (CTPS) ou Cadastro de Pessoa Física (CPF), é encaminhado a outro endereço. $\mathrm{O}$ atendimento exclusivo e especializado me levou a escolher o ônibus da Praça Onze como campo principal para esta pesquisa.

$\mathrm{Na}$ triagem, começa mais uma sexta-feira das quarenta que acompanhei ao longo do trabalho de campo, durante o qual tive acesso amplo ao ônibus. Fiz a opção metodológica pela etnografia com observação participante, por entender que tal metodologia permite reconstituir as experiências das pessoas em sua vida indocumentada e compreender as dinâmicas de atendimento do ônibus. Becker (1997, p. 75) destaca que a observação participante aborda as pessoas "enredadas em relações sociais que são importantes para elas", e são essas relações que ao cientista social interessa conhecer. Toda a pesquisa foi metodologicamente construída a partir da observação participante. Acompanhei o processo de atendimento no ônibus, que inclui: triagem, entrevistas aos usuários realizadas pelos funcionários do ônibus, audiências com os juízes e recebimento, no cartório do Juizado da Infância e da Juventude, da certidão de nascimento. Havia muitas conversas informais e observação de minha parte.

\footnotetext{
3 A Justiça Itinerante foi criada pela Constituição Federal de 1988, no artigo $125, \$ 7^{\circ}$, em emenda incluída em 2004. No Rio, começou a funcionar em 2004 (GAULIA, 2018), levando serviços judiciais a áreas pobres ou distantes, por intermédio de ônibus que percorriam as comunidades ou mutirões firmados com empresas de comunicação ou organizações não governamentais. Segundo Gaulia (2014), em 2014, a Justiça enviava seus ônibus para dezenove localidades do Estado. Em 2018, segundo a assessoria de comunicação do Tribunal de Justiça do Estado do Rio de Janeiro (TJRJ), atuava em 24 localidades. De 2004 a janeiro de 2018, realizou o total de 1.029.921 atendimentos.
} 
Selecionei histórias de vida como fios condutores na pesquisa, a partir de Langness (1973) e Schritzmeyer (2015). Sem espaço para fazer aqui a revisão de leitura necessária, destaco que, segundo Langness (1973), a história de vida oferece a possibilidade de compreender, em dados biográficos de um indivíduo, as relações entre os membros de um grupo social. Boas (1943) e Bourdieu (2011) problematizaram o conceito, alertando que a história de vida, embora útil ao permitir analisar como comportamentos individuais se relacionam a mudanças políticas, religiosas ou econômicas, pode levar ao erro de fazer generalizações baseadas em declarações de um interlocutor. Em diálogo com essa metodologia, minha opção foi mesclar a observação participante com histórias de vida, como tentativa de compreender histórias coletivas a partir das vivências individuais. Algumas histórias de vida surgem neste artigo.

Para facilitar a compreensão do leitor, esclareço que o ônibus, por dentro, é dividido em pequenos espaços. Depois do banco do motorista e quatro poltronas originais do veículo, o primeiro ambiente é um misto de secretaria e cartório, onde trabalha a escrivã da Justiça Itinerante. Os computadores são interligados ao sistema do Tribunal de Justiça, ao banco de dados do Sepec e à base de dados do Departamento Estadual de Trânsito (Detran), o que permite realizar buscas para saber se o usuário tem antecedentes criminais, trabalho que não costuma ser feito diante do interessado. $\mathrm{O}$ segundo ambiente abriga duas minissalas de audiência, com mesinhas e cadeiras, e em cada uma ficam um juiz e as pessoas atendidas. O terceiro ambiente é uma sala de audiência maior, onde fica o terceiro juiz. Um promotor e um defensor público se revezam entre as três salas para que, em cada caso, haja sempre o posicionamento da Defensoria Pública, do Ministério Público e da Justiça.

Por decisão metodológica, os nomes de todos os operadores do direito, juízes, promotores e técnicos foram trocados, a fim de proteger suas identidades. Mantive os prenomes das pessoas atendidas no ônibus, depois de perguntar a elas se preferiam que eu os alterasse. Nenhuma solicitou a alteração. De minha parte, não achei justo mudar o nome de quem por tantos anos lutou por ele. 


\section{SEM DOCUMENTOS, A MEMÓRIA COMO PROVA DA EXISTÊNCIA}

Minha primeira incursão no ônibus, muito antes da pesquisa para o doutorado, foi em dezembro de 2014, para uma reportagem sobre falta de documentação (ESCÓSSIA, 2014). À época, conheci a família de Jean, preso sob acusação de roubo. Quando Jean chegou à penitenciária Jonas Lopes de Carvalho (Bangu 4), no Rio de Janeiro, lhe pediram documentos. Ele não tinha. Nunca teve certidão de nascimento, documento de identidade, CPF, carteira de motorista ou título de eleitor. Foi identificado no sistema penal pelas impressões digitais - o que tecnicamente se chama identificação criminal ou, vulgarmente, “tocar piano". Sua mãe, Márcia, queria visitá-lo no presídio, mas, como ele não tinha documentos, era impossível.

Durante a pesquisa de campo, retomei as anotações do caso de Jean e decidi incluí-lo na tese, pois entendi que ele era crucial para o entendimento do papel da memória como produtora de verdade e por ter sido o início da reflexão sobre como, na ausência do documento, a punição chega antes dos direitos. No caso de pessoas sem documento que são presas, mais ainda. No ônibus, a orientação dos técnicos da Justiça Itinerante às pessoas atendidas era levar para as audiências, a fim de ajudar a comprovar os relatos, o que pudesse ser útil - as Declaração de Nascido Vivo (DNV) dos hospitais, certidões de batismo, documentos dos pais. Muitas vezes, porém, a prova escrita estava perdida. Percebi uma prática comum: as pessoas sem documento levavam familiares, parentes próximos e distantes, vizinhos, colegas. Na ausência dos pais, por abandono ou morte, esses testemunhos adquiriam relevância maior ainda.

Da audiência sobre o caso de Jean, preso, participavam a mãe do rapaz, Márcia, o padrasto, Luiz, uma vizinha, uma tia e algumas pessoas apresentadas como colegas de infância do rapaz. O objetivo da audiência era, a partir dos relatos daquelas pessoas, provar que Jean era quem dizia ser. Márcia (40 anos), mãe de Jean, relatou à juíza: 
"Ele nunca teve documentos porque, quando ele nasceu, logo depois eu fui presa. Artigo 157, roubo. Vacilei. Ele ficou com a tia, minha irmã, que não cuidou de registrar. Ele vacilou também. Mas é meu filho."

Depois da mãe, apresentou-se a tia, que confirmou a história. O padrasto levou fotos e boletins da escola e relembrou que, como o registro era obrigatório para a matrícula, só conseguiu a vaga por ter amizade com a diretora. Diante da autoridade judicial, pais, parentes e vizinhos começaram o processo de construção da identidade legal do indivíduo sob custódia do Estado, num trabalho de tornar verdadeira sua existência. Jean permaneceu durante anos às margens do Estado; ao cometer um crime e ser preso, tornou-se visível, mas continuou ilegível, porque, oficialmente, não existia nos registros. A tautologia classificatória de que fala Herzfeld (2016) aplicada ao acesso à documentação - se não tem documentos não é legível, se não é legível não pode ter acesso a direitos mais uma vez se confirma e, pela necessidade de punição, começa a ser desfeita. Começa o processo de dar legibilidade ao detento, e tratarei disso adiante.

$\mathrm{Na}$ audiência, a memória dos parentes de Jean se transforma em mecanismo de prova da existência dele. Halbwachs (2006) entende a memória como fenômeno social, e não apenas individual (as lembranças individuais), e considera imperativo associar memória à relação entre indivíduo e sociedade, destacando o papel do grupo na construção das lembranças. Ele associa a noção de memória coletiva à de história vivida, para além da história que se baseia em fontes, documentos e na divisão do tempo.

Pollak (1992) trata da relação entre memória e identidade, entendendo-se identidade como a imagem que a pessoa adquire ao longo da vida referente a ela mesma, imagem esta que constrói e apresenta aos outros e a si. Pollak (1992, p. 204) elabora a ideia de "enquadramento da memória”, a forma como o conjunto de lembranças de um indivíduo ou um grupo é alvo de uma disputa de sentidos, com o objetivo de construir uma identidade individual e do grupo. É uma espécie de controle de lembranças que seleciona o que de fato permanecerá na narrativa de um conjunto de acontecimentos. 
O papel da memória e da linguagem tem sido valorizado em estudos sobre migrantes e refugiados, que permitem refletir sobre identidade, imigração e documentação (DROTBOHM, 2017; FASSIN, 2014; GONZALES; CHAVEZ, 2012; JEGANATHAN, 2004; SAYAD, 1998; VERON, 2017). Sayad (1998) mostra como a condição do imigrante está relacionada a sua condição social, associada à invisibilidade social e como pessoa. Gonzales e Chavez (2012) analisam experiências de mexicanos que cruzam ilegalmente a fronteira americana, mostrando como se estabelecem sem documentação. Veron (2017), em etnografia sobre imigrantes indocumentados na Argentina, na França e no Canadá, analisa os efeitos de sentidos expressos por quem vive na clandestinidade. Drotbohm (2017), em análise etnográfica sobre migrantes de Cabo Verde, mostra como o processo de obtenção de vistos na administração burocrática se constrói de forma porosa e seletiva, criando diferenças e selecionando cidadãos elegíveis para a documentação. Além de atender formalidades e requerimentos, os candidatos passam por julgamentos morais (Drotbohm, 2017). Em estudo sobre refugiados do Sri Lanka, Jeganathan (2004) analisa o checkpoint na fronteira como um lugar de sentido onde os usuários são escrutinados e o que eles dizem é considerado ou não verdade - para lhes ser concedido um documento que se tornará chave para acesso a direitos num Sri Lanka marcado pela guerra.

Esta pesquisa não trata de imigrantes nem refugiados, mas de brasileiras e brasileiros sem documento dentro de seu país, condição que se associa à pobreza e às dificuldades com instâncias estatais. Apesar das diferenças, há diálogos possíveis nas análises sobre imigrantes e brasileiros indocumentados. Como a zona de fronteira no Sri Lanka, o ônibus da Justiça Itinerante é um checkpoint para o qual converge uma longa busca por legibilidade e reconhecimento, recontada muitas e muitas vezes. O serviço do ônibus escrutina e verifica os relatos a fim de conceder a documentação.

O diálogo com Geertz descortina a possibilidade de valorizar esses pequenos relatos, contextos particulares, diante do que poderia ser entendido como quadro legal fixo e imutável. Em dois anos de trabalho etnográfico, observei, no cotidiano de audiências do ônibus, a força das histórias individuais diante do 
que pensei serem conceitos rígidos do Direito, e a forma como tais conceitos eram negociados a cada audiência. Por lei, o primeiro registro de nascimento é gratuito para o cidadão ${ }^{4}$. Na prática, entretanto, há diferentes motivos para não ter o documento e para buscar o acesso ao registro, diferentes caminhos para comprovar a identidade e muitos meandros nesses percursos, até que o registro seja concedido.

$\mathrm{Na}$ falta de documentos, as famílias do ônibus recorrem à memória, num trabalho de acionamento de lembranças e de enquadramento, a fim de encaixar peças da história. Não se trata, como se poderia pensar, de negar crimes. No caso de Jean, o que importa é reconstruir sua trajetória de sujeito ligado àquele núcleo familiar. "É meu filho", diz a mãe. "Vacilou, foi preso", completa a tia. "Consegui vaga na escola porque conhecia a diretora", informa o padrasto. “Jogávamos futebol”, conta o vizinho, e um personagem até então invisível vai criando visibilidade. Numa operação refeita dezenas de vezes, retalhos da memória são unidos para narrar e comprovar uma existência.

\section{A HISTÓRIA DOS PRESOS INVISÍVEIS: A PUNIÇÃO CHEGA ANTES DOS DIREITOS}

A reportagem sobre Jean despertou meu interesse sobre a temática dos presos sem documento. À época, de acordo com dados da Secretaria de Administração Penitenciária do Rio de Janeiro, havia nos presídios estaduais pelo menos 3.988 detentos - 10\% da população carcerária fluminense sem documentos de identificação civil (registro de nascimento e carteira de identidade) (ESCÓSSIA, 2014). Esses detentos eram mantidos no sistema penitenciário apenas com a identificação criminal - as acusações contra eles, as impressões digitais e o "vulgo", o nome pelo qual eram mais conhecidos.

\footnotetext{
A legislação sobre o registro civil no Brasil inclui a Lei n 6.015, de 1973, que determina que o registro seja feito pelos pais nos cartórios de Registro Civil das Pessoas Naturais; a Lei n 9.534, de 1997, que torna o serviço gratuito para o cidadão; a Lei $n^{\circ} 13.112$, de 2015, que permite que a criança seja registrada pela mãe, com a indicação do nome paterno.
} 
Durante a pesquisa de campo, voltei ao assunto. Não localizei a família de Jean, mas no ônibus da Praça Onze conheci outras na mesma situação, quase sempre com mães impedidas de visitar seus filhos pela ausência de documentação delas ou deles, ou de ambos. O sistema indagava: como provar que estavam visitando filhos? Eram situações que classifico como de urgência de legibilidade: pessoas que até então haviam vivido como ilegíveis, mas que necessitavam ser legíveis pelo Estado em determinado momento, a fim de garantir um direito.

No ônibus, as mães dos presos ilegíveis se apresentavam e pediam a documentação. Ao contrário de negar crimes, tratava-se de admiti-los, reconhecer que o preso havia, sim, cometido crimes - mas eram filhos delas, e elas queriam visitá-los. Assim conheci Samia, que buscava o documento de Tyrone, preso por tráfico, e Rosemary, que acompanhava Carlos, em liberdade condicional depois de uma condenação a cinco anos de prisão por roubo. Detido por mais de três anos numa penitenciária, Carlos nunca obteve a certidão de nascimento. A cada mês, quando se reapresentava ao juiz da condicional, tinha de provar sua identidade pelas impressões digitais, como me contou em 9 de setembro de 2016:

"O difícil é convencer os caras de que eu sou eu mesmo. Não tenho nenhum papel. Eles me deram um número, tiraram digitais, conferem pra ver se sou eu. Ninguém pra me arranjar certidão de nascimento. Preso também tem direito" (Carlos, 21 anos).

Das trajetórias dos presos sem documento, uma das mais marcantes foi a de Adriano, preso desde 2014. Como ele não tinha certidão de nascimento, sua mãe, Aparecida, não podia visitá-lo, o que a levou ao ônibus. Dra. Esther, juíza do caso, marcou audiência por videoconferência: no Tribunal de Justiça, ouviria a mãe e, com o auxílio de câmeras instaladas no Complexo Penitenciário de Gericinó, Adriano. Por essa época, eu havia feito leituras sobre etnografia multissituada e decidi sair dos limites do ônibus. Para Marcus (1995), é possível falar em etnografia multissituada quando se sai dos lugares e situações locais da investigação etnográfica convencional, a fim de examinar a circulação de significados, objetos e identidades - o que, como mostra o autor, é um movimento 
que caracteriza inclusive etnografias clássicas. Embora meu campo de pesquisa fosse majoritariamente constituído e delimitado pelo ônibus, entendi que poderia investigar em outros locais. Pedi autorização judicial e, com a concordância de Aparecida, acompanhei a audiência de Adriano.

Compareci ao tribunal na data marcada, 28 de julho de 2017. A audiência foi presidida pela dra. Esther, com participação de uma promotora e uma defensora pública. Aparecida, mãe de Adriano, levou a avó do rapaz, Heloisa. No dia da audiência, Aparecida não via o filho havia três anos e nove meses, pois, como ele não tinha certidão, ela nunca conseguiu provar que era mãe dele. A história de vida de Adriano era, como a de outras pessoas que conheci no ônibus, marcada pela contínua negação de direitos. Segundo o relato de Aparecida, ele nasceu em 1990 e não foi registrado. Aparecida era muito pobre e não vivia com o pai de seus filhos. Adriano começou a cometer pequenos delitos, passando a roubar e participar do tráfico de droga. Foi preso e condenado. A juíza perguntou sobre o passado da família, e Aparecida contou que se separou do marido porque ele bebia muito e batia nela. As crianças viviam com a mãe quando o mais velho desapareceu no centro do Rio de Janeiro. Assim contou Aparecida (52 anos) durante a audiência:

"Procurei meu filho, mas nunca achei. Fiquei perdida na vida,
comecei a beber. Deixei o Adriano com a avó dele, minha mãe. O mais
novo ficou com uma tia. Sei que a fiz uma coisa horrível, dei meus
filhos, mas não conseguia criar, não conseguia nem viver direito
depois que meu filho desapareceu."

Aparecida puxou o fio da memória, e a avó de Adriano, Heloisa, ajudou. Lembrou-se de que ele morou com ela, de que pouco frequentou a escola, de como jogava bola. Relembrou o desaparecimento do neto mais velho e o alcoolismo de Aparecida. Na ausência de papéis, a memória das duas mulheres ajudou a reconstituir a trajetória de Adriano sem negar delitos - pelo contrário, assumi-los ajudava a provar que ele era o rapaz que aparecia na televisão e precisava de documento. Aparecida falou de sua culpa, repetindo o discurso que percebi em muitos outros adultos sem documento: 
"Dói ver o filho assim, preso, e não fazer nada. Se eu tivesse sido uma mãe melhor, talvez ele não estivesse aí. Mas Adriano não é um mau filho. Foram as más companhias que fizeram o Adriano roubar."

Na reconstrução da trajetória de Adriano, foi fundamental o diálogo com a mãe. O rapaz tomou a bênção da mãe que não via há três anos e nove meses. Aparecida pediu perdão ao filho. Sentada no canto, entendi que aquele pedido expressava um pedido para que ela mesma se perdoasse. Aparecida tivera uma trajetória de direitos negados: o filho desaparecido, o marido violento, o alcoolismo, a necessidade de deixar os filhos com outras pessoas. O rapaz respondeu: “Tira isso da cabeça, mãe, não tenho que perdoar nada". Aparecida e Heloisa choravam, e Adriano também estava muito emocionado.

Sem entrar no mérito da responsabilidade penal de Adriano, pois ele já fora condenado pelo crime e cumpria pena, dra. Esther discutiu com a promotora e a defensora pública pontos cruciais para este trabalho. Informou que o Sepec já realizara em vão a busca nos cartórios pelo registro de nascimento de Adriano. A Folha de Antecedentes Criminais (FAC) fora checada, e as evidências indicavam, assim, que o filho de Aparecida, neto de Heloísa, era o rapaz que aparecia no monitor de TV durante a teleconferência. Dra. Esther tratou na audiência de dois eixos basilares para esta pesquisa: o primeiro, o fato de alguém que comete crimes não estar alijado do direito à documentação; o segundo, o fato de o preso sem documento, mesmo sem identificação civil, receber assim a identificação criminal, que permite que ele entre no sistema e seja legível por esse sistema em particular - mas não no conjunto de políticas públicas.

"É como se a pessoa tivesse um RG para ser punido, apenas para responder ao processo e sofrer a punição. Entendeu? Ele não recebeu o RG verdadeiro, porque não tem certidão de nascimento. Recebeu, na prisão, o número do que será o RG quando ele tiver certidão de nascimento" (dra. Esther).

O caminho trilhado a partir de Foucault $(1987,2015)$ permite refletir sobre como o sistema prisional integra um sistema disciplinar amplo, marcado 
pela vigilância, e no qual a identificação do criminoso é instrumento de vigilância e controle. Em estudos etnográficos sobre prisões brasileiras, Mallart e Rui (2017) e Godoi (2015) ajudam na compreensão das dinâmicas do sistema carcerário nacional, com fluxos próprios, como superlotação, demora nos julgamentos e entra e sai de presos, chamado por Mallart e Rui (2017) de "cadeia ping-pong". No caso dos presos sem documento, as dinâmicas do sistema carcerário encontram uma falha capaz de ameaçar seu princípio basal: identificar o criminoso e puni-lo. Ao mesmo tempo, o próprio sistema opera uma solução para permitir a punição: identificar o detento apenas criminalmente, já que o registro civil do adulto requer investigação de antecedentes e uma decisão judicial. De modo excepcional, o documento zero daquele indivíduo não é a certidão de nascimento, o registro civil, mas o registro criminal. Preso, com a identificação criminal feita, mas sem registro civil, Adriano vivia uma situação peculiar e, no entanto, comum a presos sem documentação ${ }^{5}$. Eram legíveis para a punição do crime, mas ilegíveis para o conjunto dos direitos.

\section{“AS PESSOAS SENTEM MUITO PODER EM DIZER NÃO": DO DIREITO AOS DIREITOS}

Na sala 1 começa a audiência de Raimundo, o indígena que abre este artigo. Ele conta à juíza que procurou a Defensoria Pública e foi encaminhado ao ônibus porque quer trocar de nome. "Sou índio, né? Quero meu nome de índio", explica, mostrando documentos com o nome cristão. Nascido numa aldeia tabajara no Ceará, quer se chamar Akazu-j (pronuncia-se Akasui), nome pelo qual é conhecido pela tribo e pelos amigos do Rio de Janeiro, para onde se mudou aos 20 anos; agora tem 69. Foi biscateiro, camelô, pedreiro e, agora, é artesão. Akazu-j, diz, significa cajueiro, árvore comum na aldeia. A demanda de Akasu-j exigia negociação.

\footnotetext{
Segundo a dra. Esther, essa situação afetava aproximadamente 4.500 detentos no estado do Rio em 2017. No mesmo ano, levantamento do Departamento Penitenciário Nacional (Depen) indicava que nove de cada dez detentos brasileiros não tinham qualquer documento. A falta de documentação afetava a possibilidade de ressocialização dos presos e motivou uma cooperação entre a Associação dos Notários e Registradores do Brasil (Anoreg-BR) e o Depen para fazer o registro civil de presos em dezesseis estados (CONSELHO NACIONAL DE JUSTIÇA, 2017).
} 
Se já era registrado, por que ter outro registro? As buscas indicavam que a folha de antecedentes dele não tinha anotações criminais. Akasu-j poderia também ter procurado a Fundação Nacional do Índio (Funai) e pedido um registro de seu nome indígena. No entanto, ao buscar outra instância do Estado-sistema, a Defensoria Pública, foi encaminhado à Justiça Itinerante, e era dela que esperava uma solução.

Ao longo do trabalho de campo, pude compreender que cada caso seria um caso, que a decisão de um processo não valeria automaticamente para os demais. Cada usuário teria uma demanda, uma justificativa, e cada juiz ou juíza, uma interpretação, apesar dos princípios jurídicos legais pelos quais deveriam se pautar, entre eles a lei brasileira, a Constituição e tratados internacionais. A busca pelo direito à certidão de nascimento ou, em alguns casos, à alteração de nome tinha desdobramentos de sentido diferentes em cada trajetória desenhada na sala de audiência. Como analisa Geertz:

A parte "jurídica” do mundo não é simplesmente um conjunto de normas, regulamentos, princípios e valores limitados, que geram tudo que tenha a ver com o direito, desde decisões do júri, até eventos destilados, e sim parte de uma maneira específica de imaginar a realidade. Trata-se, basicamente, não do que aconteceu, e sim do que acontece aos olhos do Direito; e se o Direito difere, de um lugar ao outro, de uma época a outra, então o que seus olhos veem também se modifica (GEERTZ, 1997, p. 259).

O que acontece aos olhos do Direito, nesta pesquisa, acontece no entorno do ônibus da Praça Onze, mas também dentro dele, no momento da audiência. A juíza responsável pelo caso de Akasu-j ouviu a história dele e de pronto disse que autorizaria o registro com o nome indígena. “ $O$ índio não é invisível, não pode ser registrado como invisível”, justificou ela. Disse que seu pai fora um estudioso da causa indígena e que se sentia tocada pelo processo. Entendeu que era "uma questão de identidade". "Não acho complicado. As pessoas sentem muito poder em dizer não, mas para mim é uma demanda simples”, resumiu. Akasu-j foi encaminhado ao cartório e lá recebeu sua certidão de nascimento.

O caso de Akasu-j pode ser analisado em diálogo com estudos no campo da antropologia do Estado e antropologia do Direito sobre o funcionamento do 
sistema jurídico brasileiro. Torna-se crucial relembrar o entendimento proposto por Foucault $(1987,2015)$ de que normas e instituições judiciais são atravessados por dispositivos de poder, relacionados à disciplina e à governamentalidade. A perspectiva foucaultiana do documento como esfera de controle se explicita nas audiências da Justiça Itinerante. Numa outra perspectiva, DaMatta (1997) mostra que a sociedade brasileira se organiza num dilema entre práticas hierárquicas, no qual cada pessoa tem um "lugar" com direitos e deveres definidos, e relações jurídicas são representadas como igualitárias, universais. A articulação entre essas perspectivas aparece em estudos de Lima (2010), Lima e Misse (2000) e Sinhoretto (2011), permitindo questionar, no dizer de Sinhoretto (2011, p. 27),

a possibilidade de pensar a sociedade brasileira como plenamente disciplinar (no sentido foucaultiano), uma vez que a coexistência das lógicas jurídicas igualitária e hierárquica torna muito difícil a introjeção subjetiva das regras pelos indivíduos, que nunca estão bem certos sobre qual sistema de regras será validado nas interações com outros indivíduos, principalmente se eles forem agentes estatais.

Na etnografia das audiências, outro conceito que emerge é o de campo como lugar de disputa de sentidos (BOURDIEU, 1989), espaço social simbólico estruturado por relações de força, no qual se manifestam posições de poder. $\mathrm{O}$ campo jurídico é descrito por Bourdieu (1989, p. 237) como o lugar por excelência do "monopólio do discurso atuante, capaz, por sua própria força, de produzir efeitos". Os agentes desse campo, segundo o autor, são investidos da competência que lhes autoriza a interpretar textos que consagram a visão considerada justa. Sinhoretto (2007), em pesquisa etnográfica sobre a reforma da Justiça, analisa a implementação, pelo Governo do Estado de São Paulo, dos Centros de Integração e Cidadania (CIC), criados em 1996 para melhorar o acesso da população pobre à Justiça. A partir da ideia de campo jurídico de Bourdieu, a autora formula a ideia de um campo estatal de administração de conflitos (SINHORETTO, 2007, 2011) e afirma que esse campo incorpora, em seu funcionamento, informalidade e técnicas não judiciais. Assim, o campo de administração de conflitos 
Considera que práticas informais, ilegais ou não, referenciadas às leis escritas não são apenas defeitos de aplicação do Direito ou falhas na implementação da lei cometida por maus profissionais, mas são parte não negligenciável de rituais de administração de conflitos que estão em disputa no interior do campo (SINHORETTO, 2011, p. 28).

Sinhoretto (2011) reflete sobre como o campo de administração de conflitos não ficou inerte diante das pressões por reformas no Judiciário. Gaulia (2014) e Galanter (2016) demonstram de que forma a expressão “acesso à Justiça" adquire seu atual significado, associado ao benefício da assistência judiciária e à garantia de igualdade perante a lei. No Brasil, afirma Gaulia (2014), a Constituição de 1988 torna-se um marco ao incluir afirmar, em seu artigo $5^{\circ}$, dedicado aos direitos fundamentais, que cabe ao Poder Judiciário analisar lesão ou ameaça a direitos. Mais tarde, esse mesmo conjunto de demandas sociais diante de "defeitos" do sistema judicial permitiria a criação das delegacias e varas especializadas no tratamento da violência contra a mulher. A Justiça Itinerante se constitui como conquista num quadro em que o acesso à Justiça passa a ser entendido como direito - e a dificuldade de acesso, como a negação desse direito.

A análise das audiências do ônibus da Praça Onze permite refletir sobre como elas se transformam em pequenos palcos onde saberes locais são acionados na discussão de questões que perpassam o sistema de justiça e de acesso à justiça no Brasil. Em cada audiência, o que está em jogo é o acesso não só ao Direito ou à Justiça, mas aos direitos: afinal, quem tem direito a buscar direitos? Que direitos devem vir primeiro? Quem garante o direito aos direitos? Qual o papel da Justiça na garantia desses direitos?

Em dois anos de pesquisa conversei com vários juízes nas audiências. Não há um corpo fixo de magistrados dedicado à Justiça Itinerante nem ao ônibus da Praça Onze. Todos passam a semana em diferentes áreas: cível, criminal, fiscal e de família. Às sextas-feiras são voluntários para, em vez de trabalhar na vara de origem, atuar na Justiça Itinerante. Não recebem extras por isso. Cerca de dez juízes, sendo sete juízas, se repetiam mais. Seus relatos consolidam reflexões sobre o registro de nascimento como símbolo de cidadania e da falta 
de documentação como direito negado. Acrescentam outras, sobre o papel da Justiça como garantidora de direitos. Para este artigo, selecionei algumas falas dos juízes que mostram a associação entre registro de nascimento e cidadania, repetindo uma chave verificada nas falas das pessoas sem documento:

"A gente quer trazer cidadania para eles" (dr. João).

"A pessoa não se reconhece como pessoa" (dra. Carla).

"É como se a gente desse a vida, desse uma chave para abrir portas que se fecharam. Devolve a dignidade que foi roubada ou negada" (dra. Gina). "A gente vê a gratidão das pessoas. A gente insere, dá dignidade, dá nome" (dr. João).

Os relatos dos juízes remetem à ideia de direitos como "dádivas" concedidas pelas autoridades. Abrir portas, dar a vida, trazer cidadania, devolver dignidade, são resultados que os magistrados enxergam como efeito de suas ações. É a ideia de uma "autoridade bondosa" ou, pelo menos, consciente de seu poder e de seu papel social, retribuído com a gratidão das pessoas. Reis (1990) reporta reação similar nas cartas de pessoas que tiveram demandas atendidas pelo antigo Ministério da Desburocratização brasileiro, mostrando que a ação desempenhada pela autoridade pública é vista como favor, dádiva, e merece como tal o reconhecimento e a retribuição em forma de gratidão.

Ao mesmo tempo, constatei nas falas dos juízes o entendimento de que houve falha no funcionamento do Estado-sistema e de que eles, na concessão do registro, solucionam o problema a partir de suas competências burocráticas. É explícito, para os magistrados, que o usuário sem documento está sendo punido e, indiretamente, visto como culpado, quando, na verdade, era prejudicado por ela - porque a essa pessoa foi negado um direito, o registro e, a partir dessa negativa, muitos direitos ficam pelo caminho.

"A pessoa está sendo punida por uma falha do Estado" (dra. Tania).

"Eu não estou te ajudando, é direito seu" (dra. Esther). 
"As pessoas dizem que não foram competentes, não foram fortes para conseguir o registro. A prática é culpabilizar a pessoa, colocar a culpa no excluído" (dra. Tania).

"Não é só a questão do documento. Eles não conseguem outros direitos. A pessoa não se vê como pessoa de direitos. Depois que conseguem, falam pra nós: agora eu sou alguém, como se para existir a pessoa precisasse de documento" (dra. Dayse).

"As pessoas ficam envergonhadas, a gente percebe a vergonha" (dra. Sylvia). "Nós, como Estado, não conseguimos achar o registro daquela pessoa. E aí, o que fazemos? Vamos continuar prejudicando essa pessoa?" (dra. Esther).

Se os usuários atribuíam, em parte a si, em parte ao Estado, culpa por não terem documentos, os juízes são unânimes em responsabilizar o Estado pela falta de documentação. Essa responsabilização é parte do que Herzfeld (2016) nomeia como "teodiceia secular da burocracia”, em diálogo com a teodiceia religiosa de que fala Max Weber (1989). Se a teodiceia weberiana permite compreender como crenças religiosas se mantêm diante de evidências de um mundo falho, a teodiceia secular de Herzfeld (2016, p. 16) "provê as pessoas de meios sociais para lidar com o desapontamento". E, se a teodiceia religiosa busca respostas na transcendência (WEBER, 1989), a teodiceia secular permite compreender por que a burocracia se mantém.

O conceito de teodiceia secular é parte de um argumento maior, no qual eu proponho tratar a burocracia do Estado-nação como diretamente análoga ao sistema ritual de uma religião. Ambos são fundados no princípio da identidade: os eleitos como comunidade exclusiva, cujos pecados individuais dos membros não podem solapar a perfeição última do ideal partilhado por todos (HERZFELD, 2016, p. 19).

A teodiceia secular é claramente acionada nas falas dos juízes, que identificam "um sistema injusto" e cheio de "privilégios” no qual o usuário é injustamente culpado por não ter documentos, quando, na verdade, é uma vítima. Uma das falas ("nós, como Estado”) é explícita ao situar os juízes como parte desse Estado que não foi eficaz na garantia de direitos. Mais uma vez, questões 
morais entram em cena, e uma das juízas percebe isso quando critica o fato de pessoas documentadas muitas vezes reproduzirem o senso comum e culparem a pessoa sem documento por sua condição. Essa juíza me disse:

"A gente pensa na situação deles e já pensa criticando: como uma mãe engravida se não tem nem registro? Ou então algum colega ou técnico fala para a mãe: mas você tem um filho atrás do outro, não é?" (dra. Esther).

Na avaliação dela, um dos exercícios cotidianos mais difíceis de seu trabalho era evitar o julgamento moral e entender que o direito ao registro independe do fato de a pessoa ter ou não cometido crimes, ter ou não registrado seu filho mais cedo, ter ou não se preocupado com métodos anticoncepcionais. Dupret (2006) e Eilbaum (2012), em análises etnográficas sobre instâncias judiciais, explicitam a clara relação entre a administração da justiça e as moralidades, e o modo como interações entre operadores do Direito e pessoas que buscam a Justiça culminam nas ações e decisões judiciais. Pude observar como elas refletem moralidades nas audiências do ônibus do subrregistro.

Entre as falas dos juízes e dos entrevistados fica muito claro um ponto de contato: o entendimento de que o registro abre caminho para outros direitos. Nas interpretações dos juízes sobre o papel da certidão do nascimento está explícito o reconhecimento do documento como acesso a direitos e perpassa suas falas o tema da primazia de direitos: um direito deve preceder outro, numa ordem dos mais ou menos importantes? Apontei na pesquisa casos de "urgência de legibilidade", pessoas que precisam do documento imediatamente para uma cirurgia, por exemplo. Nas audiências, a pergunta que surge é outra: por que é preciso esperar o documento para garantir outro direito?

Questionei vários juízes sobre isso e não ouvi outra resposta que não alertasse para a compreensão de que, mesmo sem documento, era preciso garantir direitos prévios a pessoas ilegíveis. "Não há motivo de negar atendimento a uma pessoa por ela não ter documentos", me disse a dra. Vitória em entrevista no dia 5 de maio de 2017. Em todas as ações que recebia, dra. Vitória emitia uma ordem judicial para que, enquanto a certidão não ficasse pronta - 
pois era necessário fazer pesquisas e verificações de praxe - o usuário não fosse impedido de conseguir o que necessitava de modo urgente. Com o poder que a autoridade judicial the confere, determinava que fossem garantidos a vaga na escola, o remédio, o tratamento médico e a inscrição em programas sociais. "A gente não está fazendo favor. A gente está sanando uma falha do Estado", explicava a juíza.

"É razoável negar atendimento médico a alguém apenas pelo motivo de a pessoa não ter documentação? Não é. Entendo a necessidade de identificação, os protocolos médicos, mas a saúde não pode depender de um documento" (dra. Vitória).

Outros eixos que destaco nas falas dos juízes são a preocupação com fraudes na identificação dos usuários e o papel decisivo das diferentes interpretações:

"A gente tem que levar em consideração aspectos de segurança jurídica, sempre de olho em possíveis fraudes" (dra. Teodora).

"A gente pode se deparar com pessoas querendo apagar a identidade pretérita, alguém que foi preso e quer mudar de nome ou alguém que quer assumir a identidade de alguém que morreu" (dr. Aloisio).

"A gente tem que fazer uma reinterpretação do que é legal. A gente não aplica só a lei, tem que pesar a decisão. O Direito é isso" (dra. Teodora).

"A gente não pode ser burocrático. Tem de seguir as regras para não prejudicar a lisura do processo, mas esse trabalho exige um olhar com visão social" (dra. Vitória).

"A subjetividade está sempre presente" (dra. Tânia).

"Algum juízo de valor há. O que tentamos é fazer um registro correto, com as informações, que não seja leviano" (dra. Marília).

Em sua análise sobre o trabalho de uma Unidad Fiscal de Instrucción(UFI) num bairro da região metropolitana de Buenos Aires, Eilbaum (2012) sustenta a importância de uma perspectiva sobre o funcionamento da justiça que, em vez de priorizar apenas a "forma" - quer dizer, o arcabouço legal, a validação jurídica ou apenas "o fundo", isto é, o conteúdo de processos e decisões observe precisamente a intersecção das formas jurídicas com esse "fundo", as 
dissonâncias entre o saber técnico, as expectativas das pessoas envolvidas e as decisões judicias resultantes desse contexto.

O respeito à forma ganhava tal importância que o fundo - o conteúdo dos relatos e das decisões - perdia consistência. Mas, em outros casos, a "forma" era utilizada e moldada com o único fim de que o (um) "fundo" fosse aceito como válido. Ora se priorizava um, ora se priorizava o outro, tal como podia ser feito pelo observador com aquelas figuras dos desenhos em preto e branco (EILBAUM, 2012, p. 27).

Eilbaum (2012) observa a preocupação constante de manter o respeito à forma, a fim de que a decisão não acabasse sendo anulada por ilegalidade, e demonstra que essa preocupação não anula a incidência decisiva de moralidades sobre as decisões. No dia 2 de junho de 2017, um caso que acompanhei no ônibus me ajudou a refletir sobre a interpenetração entre esses dois eixos de que fala Eilbaum, o fundo e a forma, explicitando a preocupação com a fraude, a exigência da legalidade e o papel do juiz na interpretação da questão, ratificando a construção do saber jurídico como um saber local, no qual as ferramentas, técnicas e interpretações são decisivos.

Sônia, de 54 anos, chegou ao ônibus depois de ir ao Detran renovar a carteira de identidade e lá ser informada de que, antes, outro problema deveria ser resolvido: no banco de dados da instituição, ela tinha dois registros de nascimento, nos quais variava o nome do pai. Sônia se explicou à juíza na sala de audiências 2: o pai biológico abandonara a família, a mãe se casara de novo e o padrasto registrou a menina, fazendo nova certidão em um "cartório amigo". A juíza disse que mandaria recuperar no banco de dados do Detran a certidão com o nome do pai biológico. Sônia teria o registro original, "verdadeiro", informou. Sônia caiu em prantos. Disse que o pai biológico a abandonara, e o padrasto a criara. A juíza explicou que o registro feito pelo padrasto era falso. Sônia disse que não queria o registro com o nome do pai biológico. O caso parecia sem solução.

Da sala 3, o promotor sugeriu: "Doutora, por que a senhora não faz com base no princípio da dignidade?”. Explicou que a Constituição 
brasileira tem entre seus preceitos o fundamento da dignidade humana (BRASIL, 2018, artigo $1^{\circ}$, III), que permitiria atender a demanda de Sônia com bases constitucionais. Da sala 1, a juíza (a mesma que atendera Akasu-j) ajudou: "É possível alegar o princípio da dignidade e dizer que será dado o registro tal como solicitado pela requerente. Fui defensora pública, fizemos uma vez e foi aceito". A juíza da sala 2 relutava, afinal o registro "verdadeiro" tinha o nome do pai biológico. O constrangimento era visível. O promotor percebeu: "Se a doutora não se sentir à vontade...”. A juíza da sala 2 disse: "De fato, não me sinto". A juíza da sala 1 completou: "Mas eu me sinto! Quer mandar para mim? Faço na hora". A colega concordou, Sônia mudou de mesa e saiu com autorização para ter na certidão o nome do padrasto.

Pedi que o promotor e a juíza da sala 1 falassem do caso. O promotor explicou: embora o registro original trouxesse o nome do pai biológico, obrigar Sônia a aceitá-lo era desconsiderar sua história, pois ela fora criada pelo padrasto, e não pelo pai biológico, que a abandonara. O registro "verdadeiro" confrontava Sônia com esse abandono, enquanto o outro lhe conferia uma família. No entendimento do promotor, o princípio da dignidade, fundamento constitucional brasileiro respaldado em longa tradição jurídica, permitia aquela "licença", como chamou. A juíza da sala 1 explicou:

"Eu poderia anular o primeiro registro. Isso é certo também. É uma interpretação mais restritiva ou mais elástica. Não é certo nem errado. O Direito brasileiro tem como princípio geral a dignidade humana. Essa é a finalidade do Direito, garantir a dignidade. Minha opção foi preservar o direito à dignidade" (dra. Carla).

Ao final, a juíza mandou conceder a Sonia o registro com o nome do padrasto. E repetiu o que me dissera no processo de Akasu-j: "as pessoas sentem muito poder em dizer não", lembrou. Guardei essa frase como uma síntese do que as trajetórias das pessoas sem documento me relatavam: ao longo de suas vidas, nos cartórios, hospitais, balcões, juizados, muita gente "sentiu poder" em lhes dizer não. 


\section{"Alguma coisa tem que ser feita": a Justiça como produtora de direitos}

Na reconstituição da atuação dos juízes no ônibus, destaco em suas falas o reconhecimento de que o trabalho lhes oferece satisfação pessoal e profissional, além de, muitas vezes, comovê-los. Exige deles um olhar mais amplo, e não meramente "técnico". Fica claro o reconhecimento, pelos juízes, da relevância do trabalho, bem como a relação momentânea de proximidade com o usuário. E, mais uma vez, a ideia de que daquele juiz exige-se um perfil específico, "de sensibilidade". Por fim, o último ponto que seleciono das falas dos juízes é a discussão sobre a Justiça como garantidora de direitos e da execução de políticas públicas. Como enfrentar a questão do acesso à documentação no Brasil? O que precisa ser feito? O que o juiz pode fazer, já que, no caso do adulto sem nenhum documento, só um juiz pode garantir a emissão da certidão de nascimento? Alguns trechos destacados das conversas com as juízas e os juízes estão a seguir:

"O que não pode é simplesmente mandar a pessoa embora. Alguma coisa tem que ser feita. Toda vez que o registro é negado, o direito é negado" (dra. Conceição).

"Vejo ainda um pouco de resistência dos cartórios, medo de fazer algo errado, de ser uma tentativa de fraude. E a pessoa segue sem o direito" (dra. Hellen).

“Não vejo muita revolta, não. Quando há revolta, já é bom. A pessoa pelo menos já entendeu que foi lesada. Vejo mais apatia que revolta" (dra. Esther).

"O trabalho no ônibus é um resgate de um papel que o Estado deveria ter feito, mas agora, com um adulto, só a Justiça pode fazer. É uma forma de pacificar um conflito social e de resgatar a pessoa com cidadã, como sujeito de direitos" (dra. Margarida).

Nessas falas evidencia-se a compreensão dos juízes de que está longe a solução para o problema do acesso à documentação. É claro o entendimento do papel da Justiça como instância que não pode se abster, pois negar o registro é negar direitos. No caso de adultos sem documentos, dra. Margarida afirma: "só a Justiça pode fazer". Por fim, destaco duas falas da dra. Esther explicitando 
a violência do papel da Justiça numa sociedade violenta e sua percepção da apatia dos usuários, mais que revolta.

\section{CONSIDERAÇÕES FINAIS}

Moralidades, punição, Direito e direitos são conceitos que emergem da etnografia das audiências no ônibus da Justiça Itinerante. A luta pelo registro de nascimento reflete uma das buscas que identifiquei nesta pesquisa: a certidão de nascimento como elemento de recuperação da trajetória familiar. Para Sônia e Akasu-j, era decisiva na valorização da própria identidade, e assim foi entendido pela juíza. Esses casos dialogam com a ideia do saber jurídico como saber local, no qual “o que acontece” só acontece quando se dá aos olhos do Direito, como afirma Geertz (1997). Clara, técnica do ônibus, me alertara que eu veria diferenças entre as decisões, dependendo do juiz, embora a lei fosse a mesma.

"Para trabalhar no ônibus, não pode ser um juiz que julgue só com a lei,
porque a gente depara com casos que a lei nunca analisou. Não pode
ser um juiz que venha para cá para buscar culpados, como aconteceu
certa vez com um juiz muito famoso. Ele achou que todo mundo que
vinha pedir o registro, na verdade, tinha cometido um crime e que-
ria iludir a Justiça. Temos que ter esse cuidado? Claro, e por isso faze-
mos a busca com a Folha de Antecedentes criminais. Mas, se a gente
só enxergar isso, não faz o trabalho" (Clara, em 31 de março de 2017).

Neste artigo destaquei eixos de análise que trabalhei ao longo da tese (ESCÓSSIA, 2019), especificamente os que se entrelaçam no momento das audiências, como o lugar da memória, a punição antes do benefício e a construção da verdade jurídica. Sobre o papel da memória, a lógica de funcionamento do ônibus atribui a ela um lugar fundamental. Ao longo da pesquisa, mostrei, a partir do conceito de Jeganathan (2004), que o ônibus é um checkpoint, o lugar no qual o indivíduo vai encerrar a busca e onde receberá o documento que o tornará legível aos olhos do Estado. No checkpoint do ônibus, as vidas 
dos usuários são escrutinadas para que eles provem que são quem dizem ser; a partir dali, são emitidos para aqueles usuários documentos que se transformam em chave para acesso a direitos. Mas o ônibus é também um lugar de acolhida, e a memória é fundamental para ajudar a torná-lo um ponto de chegada no qual a busca tem a chance de se encerrar.

Sobre a primazia de direitos, as audiências revelam a inconformidade de usuários e juízes com o fato de um direito negligenciado - a certidão de nascimento - acabar servindo de desculpa para que outro seja negado. Desta pesquisa resta comprovado que o registro de nascimento, para além de sua finalidade imediata - conseguir outro documento, uma vaga em escola, o Bolsa Família é também um documento que permite o acesso a outros direitos. Facilita o acesso a políticas públicas, emprego formal e legibilidade, além de carregar consigo condições para os processos de recuperação dos laços familiares. Ao mesmo tempo, depois de tantos anos sem acesso pleno a direitos, será a certidão de nascimento suficiente para que aquelas pessoas deixem as margens, como lugares de exclusão e acesso reduzido a direitos?

Esta pesquisa foi realizada no centro do Rio de Janeiro, segunda maior cidade do país. A dificuldade que funcionários do ônibus expressaram para obter informações em outros cartórios é indicadora da falta de articulação entre instâncias, formas e lógicas do sistema de documentação, edifício burocrático crucial para o acesso a políticas públicas e direitos. Esse é um dos motivos pelos quais esta pesquisa não se encerra aqui, com o intuito de buscar novas reflexões e discutir políticas públicas para a documentação.

Este estudo permite compreender a falta de documentação como uma temática transversal, em conexão com questões como pobreza, desemprego e acesso a políticas públicas. A partir de tantos fragmentos, busco observar de que forma se constrói no campo jurídico uma história com alguma inteireza, que permita ao juiz decidir como agir na garantia de direitos. O registro de nascimento é direito de todos - mas garantir esse direito a um brasileiro adulto é uma operação em são mobilizadas muitas instâncias, como memória, conhecimento jurídico e interpretação. É um ato que se dá na intersecção permanente entre "fundo" e "forma", entre saberes formais e vivências, entre legalidades e 
moralidades. Como bem percebeu a clarividente Clara, para ser juiz no ônibus da Praça Onze, "é preciso julgar com algo mais que a lei".

\section{REFERÊNCIAS BIBLIOGRÁFICAS}

1. ABRAMS, Philip. Notes on the difficult of studying the State. In: SHARMA, Aradhana; GUPTA, Akhil (ed.). The anthropology of the State: a reader. Oxford: Blackwell Publishing, 2006. p. 112-130.

2. BECKER, Howard. Métodos de Pesquisa em Ciências Sociais. São Paulo: Hucitec, 1997.

3. BOAS, Franz. Recent Anthropology. Science, [s. l.], n. 98, p. 334-337, 1943.

4. BOURDIEU, Pierre. O poder simbólico. Lisboa: Difel, 1989.

5. BOURDIEU, Pierre. Razões Práticas: sobre a teoria da ação. Campinas: Papirus, 2011.

6. BRASIL. Constituição da República Federativa do Brasil. 55. ed. São Paulo: Saraiva Educação, 2018.

7. CONSELHO NACIONAL DE JUSTIÇA. Presos enfrentam falta de registro civil para ressocialização. Agência CNJ de Notícias, Brasília, DF, 7 jul. 2017. Disponível em: http://bit.ly/2QCbueI. Acesso em: 10 fev. 2019.

8. DAMATTA, Roberto. Carnavais, malandros e heróis. Rio de Janeiro: Rocco, 1997.

9. DAMATTA, Roberto. A mão visível do Estado: notas sobre o significado cultural dos documentos. Anuário Antropológico, Rio de Janeiro, n. 99, p. 37-64, 2002.

10. DAS, Veena; POOLE, Deborah. Anthropology in the margins of the State. New Mexico: School of American Research, 2004.

11. DROTBOHM, Heike. How to extract hope from papers: classificatory performances and social networks in Cape Verdean Visa Applications. In: KLEIST, Nauja; THORSEN, Dorte. Hope and uncertainty in contemporary African migration. New York: Routledge, 2017. p. 21-39.

12. DUPRET, Baudouin. Le jugement en action: ethnométhodologie du droit, de la morale et de la justice en Egypte. Genève: Librairie Droz, 2006.

13. EILBAUM, Lucía. "O bairro fala": conflitos, moralidades e justiça no conurbano bonaerense. São Paulo: Hucitec, 2012. 
14. ESCÓSSIA, Fernanda. Nos presídios, $10 \%$ não têm documentos. O Globo, Rio de Janeiro, 9 dez. 2014.

15. ESCÓSSIA, Fernanda. Invisíveis: uma etnografia sobre identidade, direitos e cidadania nas trajetórias de brasileiros sem documento. 2019. Tese (Doutorado em História, Política e Bens Culturais) - Escola de Ciências Sociais, Fundação Getúlio Vargas, Rio de Janeiro, 2019. Disponível em: http://bit.ly/37MD3Yg. Acesso em: 9 dez. 2019.

16. FASSIN, Didier. Compaixão e repressão: a economia moral das políticas de imigração na França. Ponto Urbe, São Paulo, n. 15, p. 1-26, 2014. Acesso em: 7 set. 2019.

17. FERREIRA, Letícia Carvalho de Mesquita. Formalidades, moralidades e disputa de papel: a administração de casos de crianças desaparecidas no Rio de Janeiro. Dilemas: Revista de Estudos de Conflito e Controle Social, Rio de Janeiro, v. 8, n. 2, p. 207-234, 2015.

18. FOUCAULT, Michel. Vigiar e punir. Petrópolis: Vozes, 1987.

19. FOUCAULT, Michel. Microfísica do poder. Rio de Janeiro: Paz e Terra, 2015.

20. GALANTER, Marc. Acesso à justiça em um mundo com capacidade social em expansão. In: FERRAZ, Leslie (coord.). Repensando o acesso à justiça no Brasil: estudos internacionais. Aracaju: Evocati, 2016. v. 2, p. 16-31.

21. GAULIA, Cristina. Justiça itinerante: ampliação democrática do acesso à Justiça. Revista de Direito da Cidade, São Paulo, v. 6, n. 1, p. 208-217, 2014.

22. GAUliA, Cristina. Políticas públicas do Poder Judiciário: ressignificação do Princípio da Eficiência de prestação jurisdicional sob a ótica do neoconstitucionalismo. Passagens, Rio de Janeiro, v. 10, n. 1, p. 104-124, 2018.

23. GEERTZ, Clifford. O saber local: novos ensaios em antropologia interpretativa. Petrópolis: Vozes, 1997.

24. GODOI, Rafael. Fluxos em cadeia: as prisões em São Paulo na virada dos tempos. 2015. Tese (Doutorado em Sociologia) - Faculdade de Filosofia, Letras e Ciências Humanas, Universidade de São Paulo, São Paulo, 2015.

25. GONZALES, Roberto; CHAVEZ, Leo. "Awakening to a nightmare": abjectivity and illegality in the lives of undocumented 1.5-Generation Latino Immigrants in the United States. Current Anthropology, Chicago, v. 53, n. 3, p. 255-281, 2012.

26. HALBWACHS, Maurice. A memória coletiva. São Paulo: Centauro, 2006.

27. HERZFELD, Michael. A produção social da indiferença: explorando as raízes simbólicas da burocracia ocidental. Petrópolis: Vozes, 2016. 
28. INSTITUTO BRASILEIRO DE GEOGRAFIA E ESTATÍSTICA. Estatísticas do Registro Civil. Rio de Janeiro, 2016. v. 43. Disponível em: http://bit.ly/2Nbvwe2. Acesso em: 2 out. 2019.

29. JEGANATHAN, Pradeep. Checkpoint: anthropology, identity and the state. In: DAS, Veena; POOLE, Deborah. Anthropology in the margins of the State. New Mexico: School of American Research, 2004.

30. LANGNESS, Lewis. A história de vida na ciência antropológica. São Paulo: EPU, 1973.

31. LIMA, Roberto Kant de; EILBAUM, Lucía; PIRES, Lenin. Conflitos, direitos e moralidades em perspectiva comparada. Rio de Janeiro: Garamond, 2010.

32. LIMA, Roberto Kant de; MISSE, Michel; MIRANDA, Ana Paula. Violência, criminalidade, segurança pública e justiça criminal no Brasil: uma bibliografia. BIB: Revista Brasileira de Informação Bibliográfica em Ciências Sociais, Rio de Janeiro, n. 50, p. 45-123, jul./dez. 2000.

33. MALLART, Fábio; RUI, Taniele. Cadeia ping-pong: entre o dentro e o fora das muralhas. Ponto Urbe, São Paulo, n. 21, p. 1-17, 2017.

34. MARCUS, George. Ethnography in/of the world system: the emergence of multisited ethnography. Annual Review of Anthropology, [s. l.], v. 24, p. 95-117, 1995.

35. PEIRANO, Mariza. De que serve um documento? In: PALMEIRA, Moacir; BARREIRA, César (org.). Política no Brasil: visões de antropólogos. Rio de Janeiro: Relume-Dumará, 2006. p. 25-50.

36. POLLAK, Michael. Memória e identidade social. Estudos Históricos, Rio de Janeiro, v. 5, n. 10, p. 200-212, 1992.

37. REIS, Elisa. Opressão burocrática: o ponto de vista do cidadão. Estudos Históricos, Rio de Janeiro, v. 3, n. 6, p. 161-179, 1990.

38. SANTOS, Wanderley Guilherme dos. Cidadania e justiça: a política social na ordem brasileira. Rio de Janeiro: Editora Campus, 1979.

39. SAYAD, Abdelmalek. A imigração ou os paradoxos da alteridade. São Paulo: Edusp, 1998.

40. SCHRITZMEYER, A. L. P. Fios da vida: crianças abrigadas, hoje adultas, diante de seus prontuários. Vivência: Revista de Antropologia, Natal, v. 1, n. 46, p. 93-112, 2015. Disponível em: http://bit.ly/37OALbg. Acesso em: 9 out. 2019.

41. SHARMA, Aradhana; GUPTA, Akhil. Introduction: rethinking theories of the state in an age of globalization. In: SHARMA, Aradhana; GUPTA, Akhil (org.). The anthropology of the state: a reader. Oxford: Blackwell Publishing, 2006. p. 1-42. 
42. SINHORETTO, Jaqueline. Ir aonde o povo está: etnografia de uma reforma da justiça. 2007. Tese (Doutorado em Sociologia) - Universidade de São Paulo, 2007.

43. SINHORETTO, Jaqueline. Campo estatal de administração de conflitos: reflexões sobre a prática de pesquisa para a construção de um objeto. In: LIMA, Roberto Kant de; EILBAUM, Lucía; PIRES, Lenin. Burocracias, direitos e conflitos: pesquisas comparadas em antropologia do direito. Rio de Janeiro: Garamond, 2011. p. 25-41.

44. LIMA, Antonio Carlos Souza (coord.). Antropologia e Direito: temas antropológicos para estudos jurídicos. Rio de Janeiro: Contra Capa, 2012.

45. VERON, Daniel. Sociologie des sans-papiers Processus d'illégalisation des migrant.e.s et expériences clandestines (Paris, Buenos Aires, Montréal). 2017. Thèse (Doctorat en Sociologie) - Université Paris Nanterre, Paris, 2017. Disponível em: http://bit.ly/37LcJxM. Acesso em: 9 out. 2019.

46. VIANNA, Adriana (org.). O fazer e o desfazer dos direitos: experiências etnográficas sobre política, administração e moralidades. Rio de Janeiro: E-papers, 2013. p. 15-35.

47. WEBER, Max. A ética protestante e o espírito do capitalismo. São Paulo: Pioneira, 1989. 